Association for Information Systems AIS Electronic Library (AISeL)

PACIS 2005 Proceedings

Pacific Asia Conference on Information Systems

(PACIS)

December 2005

\title{
Does Knowledge Reuse Make a Creative Person More Creative?
}

\author{
Pak-Keung Cheung \\ University of Hong Kong \\ Patrick Chau \\ University of Hong Kong \\ Anson Au \\ University of Hong Kong
}

Follow this and additional works at: http://aisel.aisnet.org/pacis2005

\section{Recommended Citation}

Cheung, Pak-Keung; Chau, Patrick; and Au, Anson, "Does Knowledge Reuse Make a Creative Person More Creative?" (2005). PACIS 2005 Proceedings. 28.

http://aisel.aisnet.org/pacis2005/28

This material is brought to you by the Pacific Asia Conference on Information Systems (PACIS) at AIS Electronic Library (AISeL). It has been accepted for inclusion in PACIS 2005 Proceedings by an authorized administrator of AIS Electronic Library (AISeL). For more information, please contact elibrary@aisnet.org. 


\title{
Does Knowledge Reuse Make a Creative Person More Creative?
}

\author{
Pak-Keung Cheung \\ School of Business \\ University of Hong Kong \\ amanc@business.hku.hk
}

\author{
Patrick Y.K. Chau \\ School of Business \\ University of Hong Kong \\ pchau@business.hku.hk
}

\author{
Anson K.K. Au \\ School of Business \\ University of Hong Kong \\ ansonau@business.hku.hk
}

\begin{abstract}
In a business world that everything changes fast, continuous innovation become a key strategy for survival. Knowledge management, which deals with the effective transfer and reuse of knowledge and best practices within a firm, has been theorized as one of the facilitators of organizational innovation. Yet, no organizational innovation can be achieved without the creative performance of their individual employees. This paper examines the effect of the most common type of organizational knowledge management system, that is, an intranet-based knowledge repository, on the level of creative performance of an individual. A controlled experiment was conducted on more than a hundred individuals to investigate the quantitative and qualitative levels of creativity outcomes on an open-ended business task. Their levels of baseline creativity skills were also measured in order to inspect its interaction with knowledge reuse. The results suggest that knowledge reuse resulting from this repository type of knowledge management system actually inhibits the creative performance of individuals, especially on the qualitative dimension. Furthermore, this inhibiting effect is significantly stronger on an individual with higher baseline creativity skills, making a creative person performs less creatively than an otherwise unimaginative person.
\end{abstract}

Keywords: Knowledge reuse, knowledge management, creativity.

\section{Introduction}

Entering the new millennium, business enterprises are facing more and more rapid and complex changes in their competitive environments. In order to survive, management not only needs to make decisions quickly, but also needs to make them innovatively (Kanter 1982; Mumford 2000). The abilities to generate creative ideas that are both novel and valuable are now considered to be an essential organizational resource in establishing sustainable competitive advantage (Coulson and Strickland 1991; Gillam 1993; West 2000).

The effectiveness of using information technology to facilitate individual creative performance has long been a prominent research focus (e.g. Elam and Mead 1990; MacCrimmon and Wagner 1994; Marakas and Elam 1997; Massetti 1996). With the growing interests in organizational knowledge management, the possibility of creativity support via knowledge reuse is gradually gaining attention. This paper describes an empirical study that attempts to examine the effects of knowledge reuse - provided by a intranet-based knowledge repository - on individual creativity outcome, with particular interest in the potential contingency effect of the baseline creativity of an individual. That is: (1) Does knowledge reuse enhances or delimits the creativity outcome of an individual? (2) Does the level of enhancing or delimiting effect differ on a creative person from an unimaginative person? 


\section{Theoretical Foundation}

Knowledge transfer can generally be subdivided into (1) knowledge sharing, the process by which an entity's knowledge is captured; and (2) knowledge reuse, the process by which an entity is able to locate and use shared knowledge (Majchrzak et al 2004). Knowledge reuses within organizations are typically performed for two distinct objectives: replication and innovation (Majchrzak et al 2004). Knowledge reuse for replication (KRR) focuses on knowledge acquisition through which best practices are transferred (replicated) in order to increase productivity. Knowledge reuse for innovation (KRI) focuses on knowledge integration through which other's knowledge are adapted (integrated) into one's existing knowledge stock in order to accomplish an innovative task. Majchrzak et al (2004) argue that majority of the past researches on knowledge management examined only the KRR related aspects and KRI warrants more research attention.

Creativity is the production of novel and appropriate ideas in any realm of human activity (Amabile 1997). Creativity is the first step in innovation, which is the successful implementation of those novel and appropriate ideas. Contrary to the conventional belief that creativity wholly depends on one's personality, the componential theory of individual creativity (Amabile 1983; Amabile 1988; Amabile 1997) posits that a person's social environment can have a significant effect on that person's level of intrinsic motivation; which in turn, have a significant effect on that person's creativity. The theory includes three major components of an individual's (or small team's) creativity, each of which is necessary for creativity in any given domain.

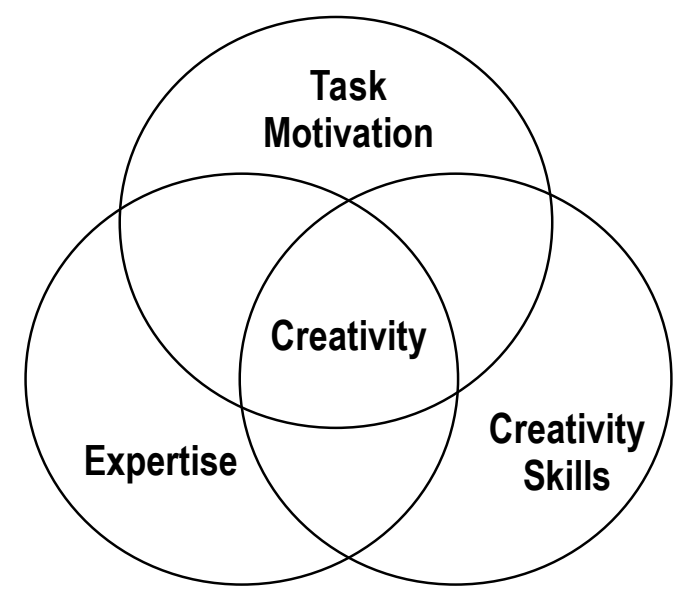

Figure 1 Three-component model of creativity (adapted from Amabile 1997)

According to Amabile (1988), domain expertise is the foundation for all creative work. It is a problem-solver's "network of possible wanderings" that includes memory for factual knowledge, technical proficiency, and special talents in the target work domain. Creative skills provide "something extra" of creative performance. These skills include a cognitive style favorable to taking new perspectives on problems, an application of techniques for the exploration of new cognitive pathways, and a working style conducive to persistent and energetic pursuit of one's work. Task motivation can be either intrinsic (driven by deep interest and involvement in a task, by curiosity, enjoyment, or a personal sense of challenge) or extrinsic (driven by a desire to attain some goal that is apart from the task itself - such as achieving a promised reward, meeting a deadline or winning a competition). Though intrinsic motivation is more conducive to creativity than extrinsic motivation, certain forms of 
extrinsic motivation may combine synergistically with intrinsic motivation; enhancing the positive effects of intrinsic motivation on creativity. These "synergistic extrinsic motivators" include informational extrinsic motivators (confirm competence or provide important information on how to improve performance) and enabling extrinsic motivators (directly increase the person's involvement in the work itself, e.g. additional resources).

\section{Research Model}

Knowledge reuse, or in a broader sense, knowledge management has been conceived by numerous practitioners as well as academics as a booster to organizational performance; especially in the areas associated with organizational innovation, such as new product development, innovation diffusion, and technology transfer. Yet, empirical evidence that supports the correlation between innovative performance and knowledge reuse is seriously lacking. The research model proposed below attempts to partially fulfill this research gap by empirically investigating the relationship between knowledge reuse and creativity outcome at an individual level. The proposed model puts knowledge reuse as a predictor of individual creativity outcome, the dependent variable of interest. This model also adheres to the componential model of Amabile (1983), which put forward that domain expertise, task motivation and creativity skills of an individual influence the creativity outcome of tasks that he or she performs. In this model, domain expertise and task motivation are taken as control variables. Thus, the levels of these two variables are measured and controlled to ensure there are no significant differences between the experimental groups on these two dimensions. And the levels of creativity skills, which are also termed as baseline creativity by other research, of the individuals are analyzed to determine its interaction effects with knowledge reuse on the creativity outcome.

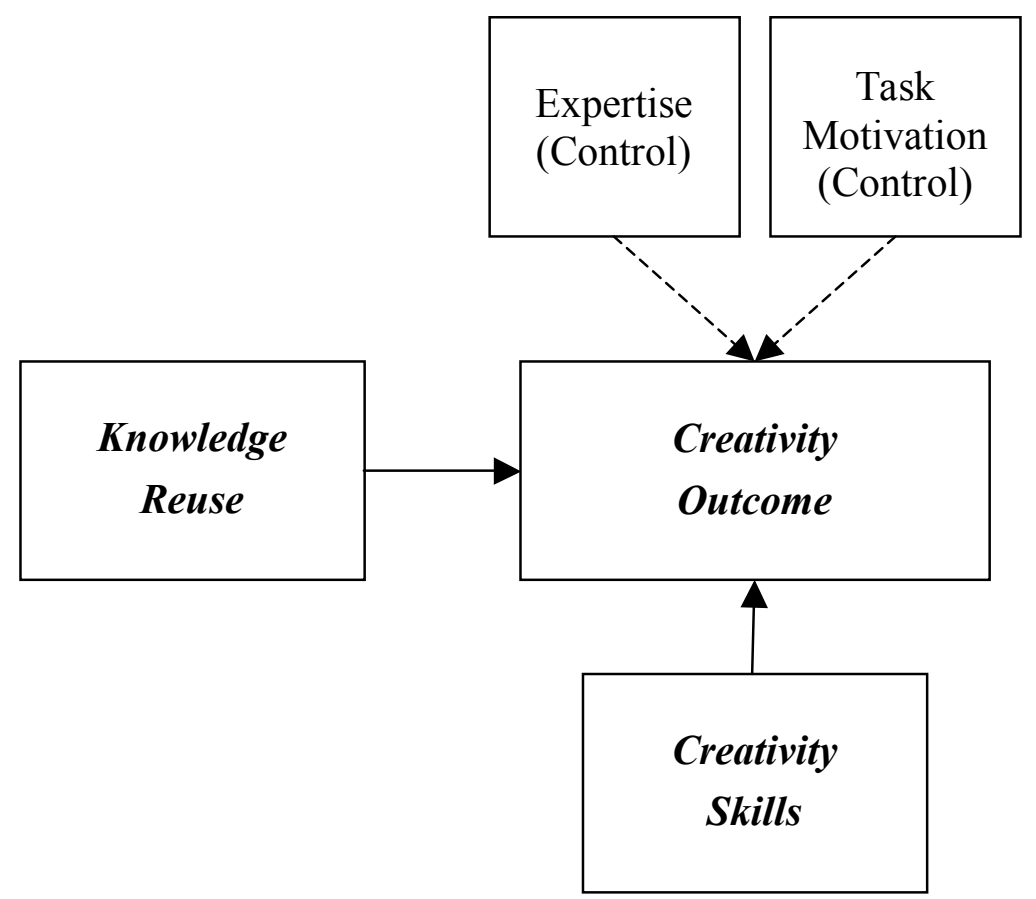

Figure 2 Research model

Knowledge reuse here refers to the adaptation of explicit knowledge (Nonaka and Takeuchi 1995) of successful practices so as to generate new and useful ideas. Surveys show that explicit knowledge repository implemented on company intranets are the prevalent type of 
knowledge management systems deployed in business organizations (Hall 2001; Hall 2002). Some researchers also argue that explicit knowledge is the only mode of knowledge that information technology can help in facilitating its share and reuse (Roberts 2000; Walsham 2001; Hislop 2002). Thus, adopting this definition of knowledge reuse pulls this study closer to the reality and allows the findings to have more relevant practical implications.

A review of previous researches that involve creativity measurement reveals that creativity outcome is in fact a multidimensional construct (MacCrimmon and Wagner 1994). Of particular importance is the distinction between the quantitative and the qualitative aspects of the construct. The former dimension is generally operationalized as the number of distinct alternatives or idea count that one can generate in a given period of time; whereas the latter dimension is operationalized in a less consistent way across the literature. Attributes such as originality, non-obviousness, workability, relevance, and thoroughness have all been used to measure the qualitative part of the construct. In this research, the measurement procedure of Massetti (1996) is followed, which integrates all these dimensions into two major ones: novelty and value. A creative performance score is calculated based on the average of these two ratings to represent the qualitative aspect of the creativity outcome.

The significance of distinguishing between the quantitative and qualitative dimensions of the creativity outcome construct is laid on the fact that the literature on creativity research does show dramatic differences, or even opposite effects of creativity support facilities on these two dimensions. For example, Durand and VanHuss (1992) find out that though creativity support software enhances the quantitative dimension (i.e. the number of alternatives); it actually inhibits the qualitative dimension (i.e. originality and inventiveness). Furthermore, the empirical findings of Elam and Mead (1990) also indicate that different software environments can both facilitate as well as impede creativity outcomes.

On the other hand, literature shows that the process of knowledge reuse for innovation (KRI) - which is the focus of this study - is significantly different from that of knowledge reuse for replication (KRR). Grant (1996) argues that when the objective is radical innovation, knowledge acquisition alone is not enough. Instead, knowledge should be integrated across disparate sources of specialized knowledge. Knowledge integration requires different mechanisms from knowledge acquisition. Furthermore, Leonard and Sensiper (1998) suggest that the content of the knowledge being shared and reused is also different between KRR and KRI. Innovation requires the transfer of largely tacit knowledge, which is hard to codify, subjective and semiconscious.

Thus, this study posits that the reuse of explicit, codified knowledge will only facilitate the quantitative part of the creativity outcome; whereas the qualitative part will be inhibited.

HYPOTHESIS 1A. Individuals who engage in knowledge reuse will generate a higher number of ideas than those who do not.

HYPOTHESIS 1B. Individuals who engage in knowledge reuse will perform less creatively than those who do not.

This study is also interested in finding out the possible interaction of creativity skills and knowledge reuse of an individual on their creativity outcome. In other words, does knowledge reuse make an already creative person even more creative? Or it makes him or her less creative than an otherwise unimaginative person? It is speculated that the influences 
(either enhancing or delimiting) of knowledge reuse on both the quantitative and qualitative aspects of creativity outcome will be stronger on the group with higher creativity skills than that of the group with lower creativity skills.

HYPOTHESIS 2A. The enhancing effect of knowledge reuse on the number of ideas generated by a creative individual is stronger than that on an unimaginative individual.

HYPOTHESIS 2в. The delimiting effect of knowledge reuse on the quality of creative performance by a creative individual is stronger than that on an unimaginative individual.

\section{Research Method}

\subsection{Experimental Design}

In the proposed model, there are two independent variables, namely creativity skills and knowledge reuse; and two control variables, namely domain expertise and task motivation. The levels of expertise and motivation were measured so as to screen out the deviant cases. By excluding these outlier cases from the final data analysis, it was ascertained that any difference in the dependent variable (i.e. the creativity of the responses) was due to the variation and manipulation of the predictor variables. Creativity skills were also measured before the experimental sessions so as to facilitate the group assignment. The experiment followed a $2 \times 2$ factorial design with creativity skills being a measured (i.e. naturally occurred) factor and knowledge reuse being a manipulated factor. Subjects were randomly assigned to each of the four groups so that their group sizes were approximately equal.

\subsection{Subjects}

Subjects were recruited from a pool of undergraduate business school students from a Hong Kong university. As the experimental task demanded only general basic knowledge on business, a sample of university students would be adequate. And as the unit of analysis of the research is at individual level without considering the social settings, generalization to commercial settings could be made quite safely.

A total of 128 students attended all necessary tests and experimental sessions. After considering the results of the tests on creativity skills, expertise and motivation, 9 were excluded because of their medial results in creativity skills, 10 were excluded due to their deviant expertise and motivation scores, and 6 were removed due to suspected data input errors, leaving a set of 103 subjects' records for final data analysis.

\subsection{Experimental Task}

The task was to generate ideas on viable e-business models to be based in Hong Kong. Subjects were given 45 minutes to generate as many ideas as they can. For each e-business model, the subject had to describe it briefly, with five basic attributes, on a card: (1) product/service idea; (2) major source of revenue; (3) target customer; (4) major competitors; and (5) competitive strategy. The rationale was to provide just enough information for the judges to assess the novelty and viability of the model, yet wouldn't put too much time burden on the subjects so that they could generate as many idea as they could without material time pressure. Each of the subjects in the "without" groups was given a brief task description and a set of blank e-business model specification cards; whilst the "with" groups 
was given, in addition, access to a web-based knowledge repository. The repository provided two levels of details about 57 existing and past winning e-business models such as Dell, Amazon, e-Bay, iTunes, etc. The information was extracted from a report published by the Hong Kong Trade Development Council titled Success Stories in Electronic Commerce. The first level of details presented a synopsis in a format that assembled the blank e-business model specification cards. Users could choose to browse the second level of details, which contained full information from the report, of any particular e-business model by clicking on a link provided in each of the synopsis page. The subjects were reminded that the details resided in the repository served only to stimulate new business ideas and as a base to develop novel ones.

\subsection{Operationalization and Measurement}

Following the approach of Elam \& Mead (1990) and Massetti (1996), the measurement of the outcome construct (i.e. creativity) was based on the subjective ratings from a panel of judges. In this experiment, a panel of 3 judges comprised of university professors in e-commerce was formed. Creativity was operationalized into two dimensions, namely the number of ideas; and a creative performance score, which is an average of the novelty and value ratings among the panel of judges (Massetti 1996; Wierenga and van Bruggen 1998). In this experiment, the number of ideas was defined as the number of valid e-business model that the subject proposed during the time period allowed in the experiment. Novelty was defined as the extent to which each response was rated as new, unique, and different. Value was defined as the extent to which each response was rated as realistic or worthwhile (i.e. the viability of the e-business models). The creative performance score was generated by averaging novelty and value ratings ${ }^{1}$ across each subject's responses.

Creativity skills were tested by the Abbreviated Torrance Test for Adults (ATTA). ATTA is a shortened version of the Torrance Test of Creative Thinking (TTCT), which is generally agreed to be the most researched and analyzed of the available instruments for creativity measurement with proven reliability and validity (Johnson and Fishkin 1999). The ATTA provides substantial insight into the creativity of adults by quantifying both figural and verbal creative strengths. It consists of four norm-referenced abilities along with fifteen criterion-referenced creativity indicators that when added together, the sum will give the creativity index. The ATTA can be scored locally and the working time is approximately 15 minutes.

According to Amabile (1983), domain expertise (i.e. domain-relevant skills) includes knowledge about the domain, technical skills required, and special domain-relevant "talent". In this experiment, the expertise on e-commerce was measured by an e-commerce test that comprised of 20 multiple choice questions selected from past test papers of an undergraduate course on e-commerce of an established university. Adopting an instrument that has been tested by thousands of subjects serves the purpose well in gauging the general technical proficiency with established reliability. Task motivation was measured by a simple self-reported questionnaire. It described a list of five tasks - one of them being the chosen task for the actual experiment - but the subjects were not told in advance which one it was. A few questions about each of the tasks were asked in order to assess their interest, curiosity,

\footnotetext{
1 Total novelty and value rating scores were generated by summing each judge's ratings on value and novelty for each subject's response set. These totals were then divided by the number of valid ideas the given subject generated to derive a mean novelty and value score for each subject. These mean scores were then averaged across judges to create a total novelty and a total value rating score for each subject (Massetti 1996).
} 
expected enjoyment, and perceived sense of challenge. A score was calculated based on their responses to the chosen task only.

\section{Results}

The raw scores on creativity skills obtained by the ATTA test, as mentioned in the previous section, were divided into "high" and "low" groups according to the median calculated based on the results of all subjects who had taken the ATTA test in this study. A total of 9 subjects, whose scores equaled to the median value, were excluded from the final analysis.

The variations of expertise and motivation were controlled by excluding the extreme cases. Ten outliers, whose scores were more than two standard deviations away from both sides of the mean, were excluded. Moreover, six were removed due to suspected data input errors where their numbers of valid e-business models had been erroneously entered, leading to great deviations in the computed average creativity performance scores. Hence, out of the initial set of 128 subjects, a set of 103 records made it through to the final analysis.

To examine the first two hypotheses that concerned about the overall influences of knowledge reuse, the baseline creativity skills grouping was collapsed so as to reduce the level of grouping from two to one, leaving only two primary experimental groups (i.e. with and without knowledge reuse groups). Two-tailed t-tests were performed on the raw scores of the other three variables (i.e. domain expertise, task motivation and creativity skills) to compare their means between the two primary experimental groups. No significant differences were found (expertise: $t=0.396, p=0.6932$; motivation: $t=-1.539, p=0.1269$; creativity skills: $t=0.463, p=0.6446)$. Thus, any difference in creativity outcome should be attributable to the predictor variable, that is, the engagement of knowledge reuse.

As all hypotheses are directional, one-tailed t-tests were performed to assess the effects of knowledge reuse on the creativity outcome of the individuals on both dimensions of the dependent variable (i.e. number of idea and creative performance). The results showed that H1A was not supported $(t=0.509, p=0.3061)$ whereas H1B was supported $(t=2.234$, $p=0.0139)$.

\begin{tabular}{|c|c|c|c|c|}
\hline & $\begin{array}{c}\text { Without } \\
\text { Knowledge Reu }\end{array}$ & & $\begin{array}{c}\text { With } \\
\text { Knowledge Reus }\end{array}$ & \\
\hline $\begin{array}{r}\text { Low } \\
\text { Creativity } \\
\text { Skills }\end{array}$ & $\begin{array}{l}\text { Number of Idea } \\
M=5.2917 \\
S D=1.7783 \\
\text { Creative performance } \\
M=3.8027 \\
S D=0.3165\end{array}$ & $N=24$ & $\begin{array}{l}\text { Number of Idea } \\
M=4.7391 \\
S D=2.1224 \\
\text { Creative performance } \\
M=3.8575 \\
S D=0.3568\end{array}$ & $N=23$ \\
\hline $\begin{array}{r}\text { High } \\
\text { Creativity } \\
\text { Skills }\end{array}$ & $\begin{array}{l}\text { Number of Idea } \\
M=5.6897 \\
S D=1.9106 \\
\text { Creative performance } \\
M=4.0111 \\
S D=0.4466\end{array}$ & $N=29$ & $\begin{array}{l}\text { Number of Idea } \\
M=5.7901 \\
S D=2.1763 \\
\text { Creative performance } \\
M=3.6695 \\
S D=0.2598\end{array}$ & $N=27$ \\
\hline
\end{tabular}

Figure 3 Group summary with means, standard deviations and group sizes 
To test the second pair of hypotheses that concerned about the interaction effects, two two-way ANOVA tests were first performed. It was revealed that there was significant interaction effect of the two factors of interest (i.e. creativity skills and knowledge reuse) on the creative performance score $(F-$ ratio $=7.9794, p=0.0057)$; but no significant interaction effect of the two factors on the number of ideas $(F$-ratio $=0.6784, p=0.4121)$.

Several follow-up t-tests showed, given that knowledge reuse was facilitated, the number of ideas that individuals were able to generate was higher for those who have higher creativity skills, and lower for those who have lower creativity skills $(t=1.721, p=0.0458)$. However, the differences in the number of ideas generated between the two experimental groups (i.e. with or without knowledge reuse) were not significant both for the individuals that have higher creativity skills or lower creativity skills. The difference in the number of ideas generated between those who have higher creativity skills and lower creativity skills, given that knowledge reuse was not adopted, was also not statistically significant. Thus, H2A was partially supported. This was also reflected by the two unparallel lines in the graph shown below.

Number of Idea

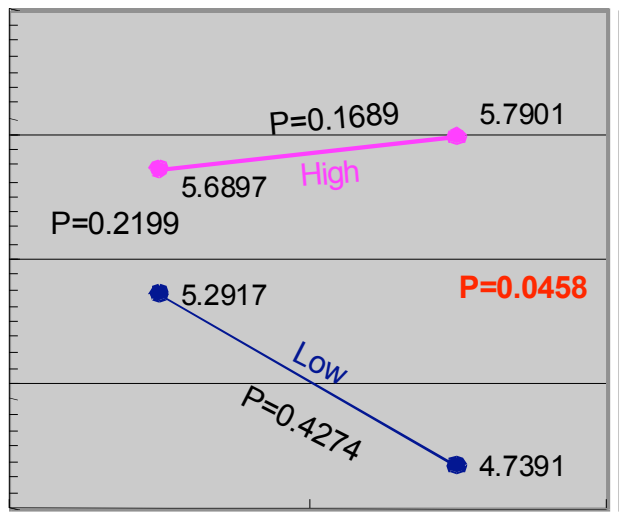

Without

With

\section{Creative Performance}

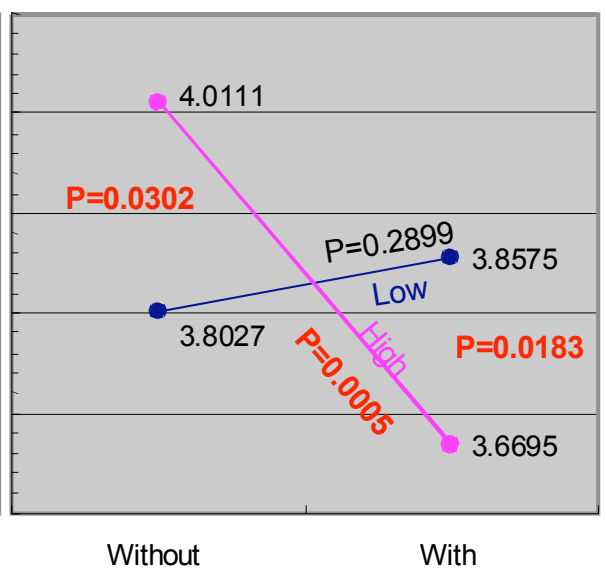

Figure 4 The interaction of knowledge reuse and creativity skills on creativity outcome with t-tests results

On the contrary, the interaction effect of the two factors on the creative performance was much more evident. When knowledge reuse was not facilitated, the creative performance (i.e. the value and novelty of ideas generated) were higher for those who have higher creativity skills, and lower for those who have lower creativity skills $(t=1.920, p=0.0302)$. The interesting part is when knowledge reuse was facilitated; individuals who have higher baseline creativity skills become less creative, and individuals who have lower baseline creativity skills become more creative $(t=-2.150, p=0.0183)$. The drop in creative performance of those who have high creative skills when comparing the two experimental groups were also highly significant $(t=3.465, p=0.0005)$. Thus, H2B was strongly supported by the evidence collected from this experiment.

\section{Discussion}

It can be seen from the results that the findings on the qualitative dimension of creativity outcome are exceedingly conclusive and indicative. The results from the control group that perform the task without any aids for knowledge reuse is consistent with the study's expectation. That is, the individuals with higher baseline creativity skills perform 
significantly better on the assigned task than those with lower baseline creativity skills. That also confirms the reliability and consistency of the baseline creativity skills test (i.e. the ATTA test) and the business task as a creativity performance measurement tool. What is most informative is that the facilitation of knowledge reuse actually reverses the situation of the "without" group, making a creative person perform worse than an unimaginative person. This indicative result may be explained by the nature of the knowledge reuse facility employed, which largely contains explicit knowledge without any brainstorming and alternative evaluation facilities. Unfortunately, this repository type of knowledge management system (Alavi 2000) also represents the majority of systems that are currently running in the business firms. This implies that the creativity of the employees working in those firms, and thus the organizational innovation, would probably be delimited by the system, leading to a negative return on investment of the knowledge management system development initiative.

However, this finding should not be interpreted as a rejection on the possibility of successful knowledge management systems or IT-enabled creativity support systems. Several previous researches have already established the effectiveness of those systems, provided that the systems are properly designed to facilitate the innovation process. For example, Elam and Mead (1990) demonstrated that two versions of a creative support systems which led to opposite results in qualitative creative performance. The version that looks backwards for causes and depth of understanding actually results in a better average performance than the version that looks ahead for practical solutions; whereas the performance of the control group with no software facilitation falls in the middle. MacCrimmon and Wagner (1994) also established that with properly designed creativity enhancement software, which adheres to the three-stage conceptual model of the creative problem solving process, the quality of creativity outcome can be greatly enhanced. Thus, firms should focus their efforts on the design of the systems rather than just adopting a single-minded "build and promote" approach, which may inhibit the creativity of their otherwise creative workers and cause negative impact on their organizational performance.

The results on the quantitative dimension are less conclusive. Overall, the individuals who use the knowledge repository generate slightly less number of ideas $(M=5.51$ vs. $M=5.31)$ than the ones who do not. But the difference is not statistically significant. Also, the effects of using the knowledge repository on individuals who have higher creativity skills and those who have lower creativity skills are also not significant. However, since the difference between the individual with higher creativity skills and those with lower creativity skills, provided that the repository is used, is statistically significant. It can be said that the use of the knowledge repository does maintain, if not widen, the gap between the quantitative creative performance of these two groups. That is, even a minimally designed repository with largely explicit knowledge can benefit the users in terms of the idea count. However, the novelty and value of these ideas may be seriously in doubt (as evidenced by the statistical significance of H1B and Н2B of the study's empirical finding described above).

\section{Limitations and Future Research}

One of the limitations of this research is that the subjects were not rewarded in any way for participating in the test and experimental sessions other than to partially fulfill their attendance requirements ${ }^{2}$. They were also not provided any incentive to perform well in the

\footnotetext{
2 The experimental sessions are conducted in the tutorial classes of the students. Their attendance partially contributes to their final mark earned in the continuous assessment portion of the course that they are taking.
} 
experiment, in which they were asked to generate as many creative ideas as they can. What drove them was purely their intrinsic motivation on the specific task that was assigned to them. This was done deliberately as task motivation was one of the controlling factors in the proposed research model. Providing any of these incentives may induce systematic influence on the data collected thus bias the findings of this research. Having said that, performing tasks driven by extrinsic motivation does more closely resemble the real life situation in industrial settings. The external validity of this research may thus be enhanced.

Another limitation of the study is that due to the time limit on each tutorial, the test sessions (on domain expertise, task motivation and creativity skills) and the experimental sessions cannot be all scheduled consecutively or on the same day. This greatly increases the possibility that a subject may not attend all three of the required tests and the experimental session, resulting in around $13 \%$ loss of usable records. Fortunately, the final sample size of 103 subjects (splitting into 4 groups) is still rather acceptable for the statistical procedures performed.

Moreover, only an online repository type of knowledge management system (KMS) is employed in this study. Though it is the prevalent type of KMS that is being utilized in most of the organizations nowadays, other types of KMS are slowly emerging. For example, it would be interesting to see how a network type KMS (Alavi 2000) would stimulate possibly other modes of knowledge reuse that may have different pattern of influences on individual creativity outcome and/or interact with the baseline creativity of an individual in a dissimilar way.

Undeniably, this is only an early attempt in understanding the determinants and the process of KRI. There are still quite a lot of themes that warrant future research efforts. For example, what mode (tacit vs. explicit), type (descriptive vs. procedural vs. reasoning), domain (subject area or problem domain), conceptual level (automatic vs. pragmatic vs. systematic vs. idealistic), and usage (practical vs. intellectual vs. recreational vs. spiritual vs. unwanted) of knowledge (Holsapple 2003) are particular favorable on knowledge reuse for innovation? Would the attributes of individual that has been proven to determine the effectiveness of KRR, such as absorptive capacity (Cohen and Levinthal 1990) and retentive capacity (Szulanski 1996, 2000), also apply to KRI? Would the factors affecting the decision for knowledge adoption (Sussman and Siegal 2003) differ between KRR and KRI?

Creativity does not arise from vacuum; nor does it depend wholly on one's personality. External facilitation such as knowledge reuse does have significant effect on one's creativity performance. By understanding how the determinants influence individual creativity and how they interact with each others, management is better equipped to develop a suitable organizational environment for the seeds of creativity to grow. It is hoped that this paper would contribute to the understanding of the relationship between knowledge reuse and individual creativity, and serve as a catalyst for future research in the arena of KRI. 


\section{References}

Alavi, M. "Managing Organizational Knowledge" in Framing the Domains of IT Management: Projecting the Future ... Through the Past, Zmud, Robert W. (Ed), Pinnaflex Education Resources, 2000, pp. 15-28.

Amabile, T. M. "A Model of Creativity and Innovation in Organizations," in Research in Organizational Behavior, B. Staw and L.L. Cummings (Eds), Vol. 10, Greenwich, CT: JAI Press, 1988, pp.123-167.

Amabile, T. M. "Motivating Creativity in Organizations: On Doing What You Love and Loving What You Do," California Management Review (40:1), Fall 1997, pp.39-58.

Amabile, T. M. "The Social Psychology of Creativity: A Componential Conceptualization," Journal of Personality and Social Psychology (45:2), 1983, pp.357-377.

Cohen, Wesley M. and Levinthal, Daniel A. "Absorptive Capacity: A New Perspective on Learning and Innovation”, Administrative Science Quarterly (35:1), March 1990, pp. 128-152.

Coulson, L. and Strickland, A. “Applied Creativity,” Executive Excellence (8), August 1991, pp. 8-9.

Durand, Douglas E. and VanHuss, Susie H. "Creativity Software and DSS: Cautionary Findings,” Information \& Management (23:1), July 1992, pp. 1-6.

Elam, J. J. and Mead, M. “Can Software Influence Creativity?” Information Systems Research (1:1), March 1990, pp.1-22.

Eysenck, H. J. "The Measurement of Creativity," in Dimensions of Creativity, M. A. Boden (Ed), MIT Press, Cambridge, MA, 1994, pp. 199-242.

Gillam, T. K. "Managing the Power of Creativity," Bank Marketing, December 1993, pp. 14-19.

Grant, R. M. "Prospering in Dynamically Competitive Environments: Organizational Capabilities as Knowledge Integration,” Organization Science (7:4), 1996, pp. 375-387.

Hall, H. "Input Friendly Intranets: Motivating Knowledge Sharing Across Intranets," Journal of Information Science (27:3), 2001, pp. 139-146.

Hall, H. "Sharing capability: the development of a framework to investigate knowledge sharing in distributed organizations." In Proceedings of the Third European Conference on Organizational Knowledge, Learning and Capabilities, 5-6 April 2002, Athens, Greece (CD ROM). Athens: Alba.

Hislop, D. "Mission Impossible? Communicating and Sharing Knowledge via Information Technology," Journal of Information Technology (17), 2002, pp. 165-177.

Holsapple, C.W. "Knowledge and Its Attributes," in Handbook on Knowledge Management 1, Holsapple, C.W. (Ed), Springer, 2003.

Johnson A. S. and Fishkin, A. S. "Assessment of Cognitive and Effective behaviors related to Creativity." in Investigating creativity in youth: Research and methods, A. S. Fishkin, B.

Cramond, \& P. Olszewski-Kubilius (Eds), Hampton Press, Cresskill, N.J., 1999, pp. 256-306. 
Kanter, R. "The Middle Manager as Innovator," Harvard Business Review (60), July/August, 1982, pp. 95-103.

Leonard, D. and Sensiper, S. "The Role of Tacit Knowledge in Group Innovation," California Management Review (40:3), 1998, pp. 112-131.

MacCrimmon, K. R. and Wagner, C. "Stimulating Ideas Through Creativity Software," Management Science (40:11), 1994, pp.1514-1532.

Majchrzak, A., Cooper, L. P. and Neece, O. E. "Knowledge Reuse for Innovation," Management Science (50:2), February 2004, pp. 174-188.

Marakas, G. M. and Elam, J. J. "Creativity Enhancement in Problem-Solving: Through Software or Process?” Management Science (43:8), 1997, pp.1136-1146.

Markus, M. L. "Toward a Theory of Knowledge Reuse: Types of Knowledge Reuse Situations and Factors in Reuse Success," Journal of Management Information Systems (18:1), Summer 2001, pp.57-93.

Massetti, B. "An Empirical Examination of the Value of Creativity Support Systems on Idea Generation," MIS Quarterly (20:1), March 1996, pp. 83-97.

Mumford, M. D. "Managing creative people: strategies and tactics for innovation," Human Resource Management Review, (10:3), 2000, pp.313-351.

Nonaka, I. and Takeuchi, H. The knowledge-Creating Company, New York: The Free Press, 1995.

Roberts, J. "From Know-how to Show-how? Questioning the Role of Information and Communication Technologies in Knowledge Transfer," Technology Analysis \& Strategic Management (12:4), 2000, pp. 429-443.

Sussman, S.W. and Siegal W.S. "Informational Influence in Organizations: An Integrated Approach to Knowledge Adoption", Information Systems Research (14:1), 2003, pp.47-65.

Szulanski, Gabriel. "Exploring Internal Stickiness: Impediments to the Transfer of Best Practice Within the Firm", Strategic Management Journal. Vol.17 (Winter Special Issue), 1996, pp. 27-43.

Szulanski, Gabriel (2000). "The Process of Knowledge Transfer: A Diachronic Analysis of Stickiness", Organizational Behavior and Human Decision Processes (82:1), May 2000, pp. 9-27.

Walsham, G. "Knowledge Management: The Benefits and Limitations of Computer Systems," European Management Journal (19:6), 2001, pp. 599-608.

West, M. A. "Creativity and innovation at work," in Innovative theories, tools, and practices in work and organizational psychology, M. Vartiainen, F. Avallone, \& N. Anderson (Eds.), Goettingen: Hogrefe \& Huber, 2000, pp. 1-14.

Wierenga, B. and van Bruggen G. H. "The Dependent Variable in Research into the Effects of Creativity Support Systems: Quality and Quantity of Ideas," MIS Quarterly (22:1), March 1998, pp. 81-87. 